\title{
Developing a survivorship care plan (SCP) delivery process for patients and primary care providers serving poor, rural, and minority patients with cancer
}

\author{
Bernard Tawfik $^{1,2}$ (1) $\cdot$ Shoshana Adler Jaffe ${ }^{3} \cdot$ Lisa Mohler $^{1} \cdot$ Jamina Oomen-Hajagos $^{1} \cdot$ Inigo San Gil $^{1}$ • \\ Rachel Chamberlain ${ }^{5}$. Suzanne Gagnon ${ }^{1}$ - Miria Kano ${ }^{1,3}$. Amy Gundelach ${ }^{1}$. Shawnia R Ryan ${ }^{1}$ • Janet Abernathy ${ }^{1}$. \\ Charles Wiggins ${ }^{4} \cdot$ Andrew Sussman $^{1,3,5} \cdot$ Zoneddy Dayao $^{1,2}$
}

Received: 27 August 2020 / Accepted: 3 February 2021 / Published online: 15 February 2021

(C) The Author(s), under exclusive licence to Springer-Verlag GmbH, DE part of Springer Nature 2021

\begin{abstract}
Background Survivorship care plans (SCPs) summarize patients' treatment and act as an education and communication tool between oncologists and primary care providers (PCPs). But creation and delivery of SCPs are challenging, labor intensive, and costly. The University of New Mexico Comprehensive Cancer Center (UNM CCC) treats a poor, rural, and minority patient population, and our purpose was to implement and evaluate a process to create and deliver SCPs to patients and PCPS.

Methods Providers placed an electronic SCP order, basic information was imported, and staff compiled treatment details. Flagged SCPs were then ready for delivery, providers approved of and delivered the SCP at the next encounter, and the SCP was sent to the PCP.

Results By April 2020, 283 SCPs were ordered, 241 (85.2\%) were created by the designated staff, and 97 (34.2\%) were given to patients after definitive therapy for breast cancer $(59.1 \%)$, gynecological cancers $(10.8 \%)$, prostate cancer $(7.4 \%)$, colorectal cancer $(5.1 \%)$, and lymphomas (4.8\%). Of 97 SCPs eligible to be sent to PCPs, 75 (77.3\%) were mailed or sent via EMR. Of the $41(48.9 \%)$ SCPs sent via mail or fax, only $8(8.3 \%)$ were received and $5(5.2 \%)$ integrated.

Conclusions This study shows that SCPs can be delivered to patients in a poor, rural, and minority patient population but that PCP receipt and integration of SCPs are poor. Future efforts need to ensure that an oncologist to PCP education and communication tool is able reach and be integrated by PCPs.
\end{abstract}

Bernard Tawfik

btawfik@salud.unm.edu

1 University of New Mexico Comprehensive Cancer Center, MSC 07-4025, 1 University of New Mexico, Albuquerque, NM 87131-0001, USA

2 Department of Internal Medicine, Division of Hematology and Oncology, University of New Mexico, MSC 07-4025, 1 University of New Mexico, Albuquerque, NM 87131-0001, USA

3 Behavioral Measurement and Population Science, Comprehensive Cancer Center Shared Resource, UNM Comprehensive Cancer Center, MSC 07-4025, 1 University of New Mexico, Albuquerque, NM 87131-0001, USA

4 Department of Internal Medicine, Division of Epidemiology, Biostatistics, and Preventive Medicine, UNM Comprehensive Cancer Center, MSC 07-4025, 1 University of New Mexico, Albuquerque, NM 87131-0001, USA

5 Department of Family and Community Medicine, UNM Comprehensive Cancer Center, MSC 07-4025, 1 University of New Mexico, Albuquerque, NM 87131-0001, USA

Keywords Survivorship care plans · Primary care providers . Cancer survivorship $\cdot$ Electronic health records $\cdot$ Delivery

\section{Introduction}

The number of cancer survivors is rapidly growing due to increased screening and improved treatment [1]. The aging population is also increasing in the USA such that cancer is becoming more prevalent [2]. Communication and education between oncologists and primary care providers (PCPs) after patients' definitive cancer treatment have been lacking [3-6]. Survivorship care plans (SCPs) summarize the patients' treatment, provide education to the PCP and patient about cancer survivorship, and are a communication tool between oncologists and PCPs [7-9]. SCP distribution has been endorsed by the American Society of Clinical Oncology [10], the Commission on Cancer (COC) [11], and the American Cancer Society [12]. Studies have shown that patients and primary care providers are generally satisfied with receiving 
SCPs [13]. PCPs are engaged in survivorship care but feel unprepared, unclear about delegation of responsibilities and lack training [14]. However, scant existing research supports the efficacy of SCPs to improve cancer survivors' outcomes $[15,16]$. Additionally, SCP distribution by oncology practices has been limited [17-19]. Creation and delivery of the SCPs have been labor intensive and costly for many healthcare systems [20,21]. Confirmation of delivery of SCPs to PCPs has only been confirmed in select programs either by mail or electronically $[22,23]$. However, numerous programs do not send SCPs to PCPs and/or do not confirm receipt of the SCP by the PCP [24, 25]. It is not well-documented how often SCPs sent by oncologists are actually received and integrated by PCP practices.

In addition to the above challenges, the University of New Mexico Comprehensive Cancer Center (UNM CCC) treats a diverse patient population with low socioeconomic status (SES) (poverty rate 19.7\%), who reside in rural areas $(22.6 \%)$ and are ethnic/racial minorities (Native Americans and Hispanics constitute $10.4 \%$ and $48 \%$ of the population, respectively). Creation and distribution of SCPs to patients and PCPs in Latino breast cancer survivors have been successfully reported [26]. But little data exists regarding rural patient populations who are at high risk of poor outcomes in addition to delivery of SCP to PCPs who will need to take on more survivorship care responsibilities as the number of survivors increase. Our work contributes to the growing body of literature surrounding the role of the PCP in survivorship care.

Our purpose was to implement and evaluate an EMR-based process to create and deliver SCPs to patients and their PCPs, including PCP receipt of the SCPs and integration of care recommendations. Outlining these initiatives is important practically so other institutions may be able to implement similar programs and scientifically so we may better understand SCP implementation in poor, rural, and minority patients.

The goal of the this project was 400 respondents with $50 \%$ of eligible patients to have a personalized SCP created, $50 \%$ of those created SCPs delivered to patients, and $50 \%$ of those SCP delivered to patients to also be delivered to the PCPs based on the 2016 COC standards for 2018 [11]. Similar non-randomized studies showing various delivery rates of SCPs to patients; $11.2 \%$ [27], $67.6 \%$ [22], $12 \%$ [28, 29] $11 \%[30], 86 \%[24,31]$. Several similar non-randomized studies did not track rates of SCP delivery to PCPs so there was not a well-defined target goal for this metric and $50 \%$ was selected as a realistic goal [32-35].

\section{Methods}

Implementation In 2019, the UNM CCC formed a committee lead by the chief medical officer with representation from oncology providers, nurses, IT, medical records, behavioral and population sciences, front office registration staff, and genetics to create a system-wide process utilizing the existing electronic health record (EHR) which launched March 2020 (Fig. 1). This program was deemed "Not Human Research" but quality improvement by the Institutional Review Board. Twelve SCPs based on ASCO and Society of Gynecologic Oncology (SGO) templates were created by the Cancer Center Certified Genetic Counselors (CGCs) and the IT team including a generic template used for all other cancers not represented by a site specific template $[12,36]$. Additionally, CGCs and medical oncologists internally developed templates included lymphoma, Hodgkin lymphoma, and melanoma. All templates included education for the PCP and patient about cancer survivorship, future surveillance schedule, and latent side effects.

The current EMR system was not designed to deliver SCPs to patients and PCPs, so EMR functions were creatively repurposed. In the first step of this process, providers identified eligible patients and submitted electronic SCP orders. Next, CGCs were notified that an SCP order had been placed. CGCs then selected the appropriate SCP template based on cancer type. The SCP was then populated using information from the EMR and included information such as demographics, oncology providers, and PCP information. The CGCs entered additional information in the SCP template including treatment dates, surgery performed, radiation delivered, chemotherapy used, surveillance schedule, stage, hormonal and molecular status. Then, the CGCs flagged the SCPs as "ready for delivery" in the EMR system. At the patient's next routinely scheduled visit, the provider received a notification that the SCP was ready to be delivered. The next routinely scheduled visit was typically a surveillance visit with a medical oncologist, surgical oncologist, gynecological oncologist, or an advanced practice provider.

The provider reviewed, approved, printed, and gave the hardcopy SCP to the patient with counseling about the purpose of the SCP during the visit. Once printed, the EMR automatically alerted the medical records department, which sent the SCP to the PCP via mail, fax, or internal EMR routing depending on the PCP practice location and communication preferences.

SCPs were sent to PCPs with a cover letter explaining the SCP purpose and providing UNM CCC contact information. SCPs sent via internal EMR routing did not trigger an alert or go to the PCPs inbox. Rather, the SCP immediately appears in the patient's medical record, but chronologically appears in the EMR based on the date of the cancer diagnosis, not the date the SCP was approved. SCPs sent to PCPs who do not utilize the internal EMR system were mailed on a passwordprotected $\mathrm{CD}$ with a separately mailed letter containing the password per usual UNM CCC protocol for all mailed medical records. In order for the SCP to be faxed to a provider, the provider's office must already have completed security paperwork on file at the UNM CCC indicating a verified fax number to ensure the integrity of the health care information. 


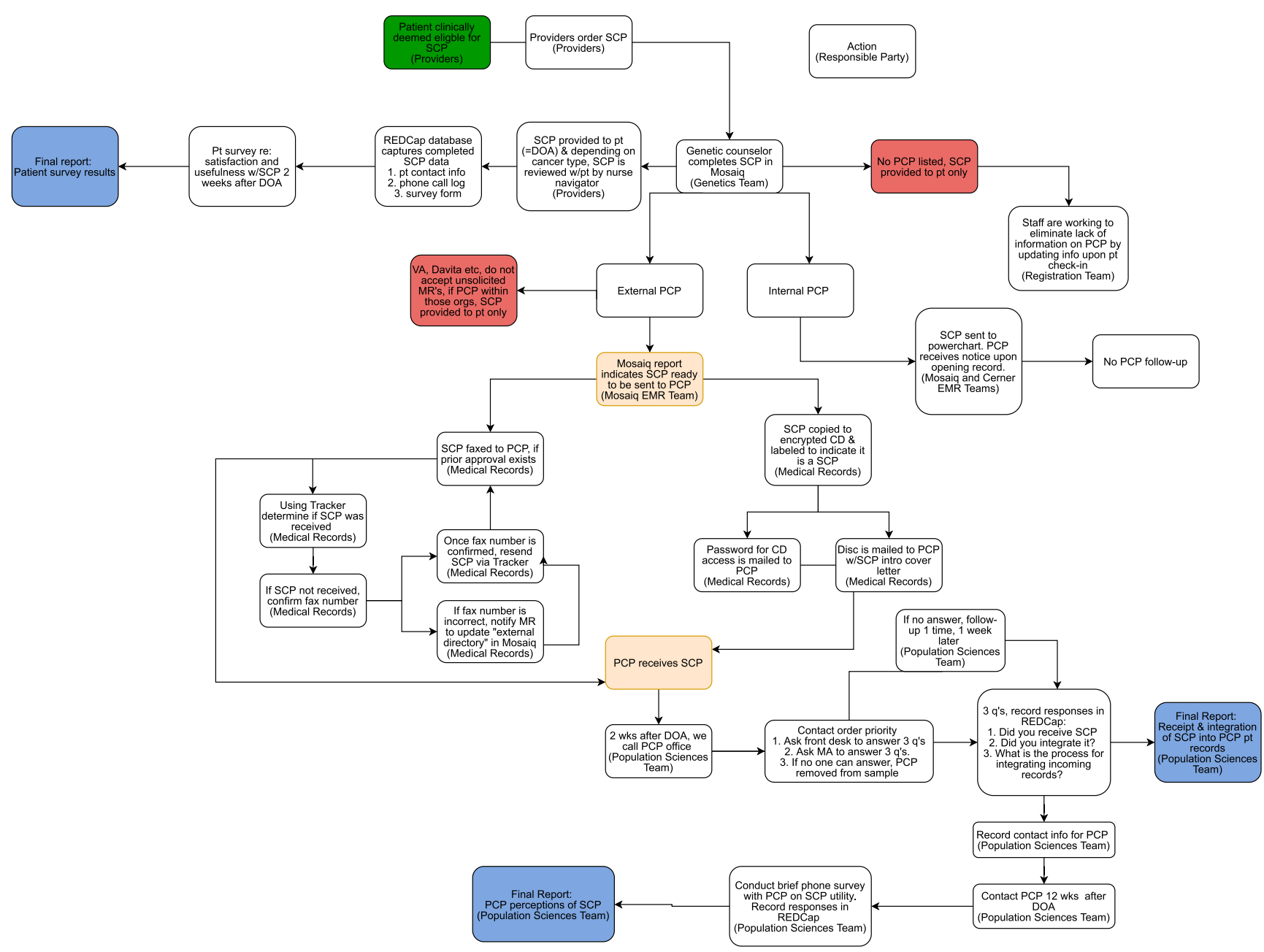

Fig. 1 Flowchart for SCP creation, patient delivery and PCP delivery

Two weeks after the SCP was sent via fax or mail, the PCPs office was contacted by the team research data specialist (RDS) via phone. The purpose of this call was to determine if the SCP had been received and if it had been integrated into the medical record. Using PCP contact information listed in the EMR, the RDS called each office and spoke with whomever answered the phone and recorded the role of this individual at the PCP office. Most commonly, the RDS spoke with the medical records department or a member of the PCP's clinical team (medical assistant or nurse). The RDS asked each office the following question: "Was the SCP document for the specified patient received?". If the office indicated they had not received the document, the RDS asked them to clarify if they accept unsolicited medical records and if they had the technology to open records on a CD. The RDS also asked the primary care office what the preferred modality of receiving medical records was at their office (e.g., faxed records or mailed records). The responses to these questions were recorded. If the office was able to confirm that the electronic or hardcopy of the SCP had been received, the RDS asked a follow-up question: "Has the document been incorporated into the patient's medical record?". We classified an SCP as having been incorporated into the medical record if staff at the PCP office were able to confirm that the document was physically or electronically present in the patient's record. If the office confirmed that they had received the document but had not placed the document in the patient's records, we asked them to describe the process for ensuring such documents are eventually integrated into the medical record. This yielded qualitative data that was recorded by the RDS conducting the phone calls.

All calls made to PCP offices were conducted by the same RDS to ensure consistency. The qualitative responses were grouped into categories during the analysis phase of the program. These categories included: PCP no longer at this location, unable to access $\mathrm{CD}$, unaware of/have not received SCP, and practice does not accept outside records. PCP offices were called up to three times in an attempt to ascertain responses to the questions listed above. The lag time between a provider's order for an SCP and the patient's next follow-up visit was 
estimated as three months, so referrals from less than 3 months prior were not counted in the denominator of SCPs ordered by providers to allow time for creation and delivery.

Data collection Multiple time points were collected for analysis via the EMR by the IT Team as each of the following events triggered a timestamp in the EMR: time from cancer diagnosis to SCP ordered, SCP ordered to SCP created, SCP created to hardcopy SCP delivered to patient by provider, and rate and route of delivery of SCPs to PCPs. Additionally, receipt and integration of SCP by PCPs were collected via telephone calls to primary care offices along with possible reasons for non-receipt and non-integration of the SCP by the RDS as mentioned above. Demographic information such as diagnosis, age, sex, income level, insurance type, zip code to assess rural status, and race/ ethnicity was collected by the IT staff. To ensure validity and reliability, each component of the SCP process was tracked separately with a separate goal so as to allow objective assessment of non-functional process components for improvement.

Recruitment and sampling All patients at the UNM CCC were recruited into this study if they were a cancer survivor after completion of definitive therapy for curable cancer. Individual medical oncologists, surgical oncologists, gynecological oncologists, and their respective advanced practice providers selected patients who were appropriate for the SCP creation program in the outpatient oncology clinic at their previously scheduled visits for surveillance or post-operative care. Screening took place from completion of definitive therapy to 1 year after cancer diagnosis per original COC 2016 standards for SCP delivery.

Analysis Statistical analysis was descriptive. Indigent was defined as those patients that qualify and obtain insurance plans for people whose income is below the federal poverty level such as Medicaid, UNM financial assistance, county financial assistance, or self-pay. Indigent population was identified to highlight the poor economic status of this population as well as income level, both of which are markers of poor cancer outcomes [37]. All patients were included in the sampling timeframe and analysis, whether indigent or not as indigent was only used as a demographic to show the poor economic status of those patients. Rural residency was defined per Centers for Medicare and Medicaid Services which relies on the United States Census Bureau's definition of rural areas which are not urban area (UA) with population of 50,000 or more or urban cluster (UC) with a population of at least 2,500 and less than 50,000 [38-40].

\section{Results}

By April 2020, 283 SCPs are ordered by providers for eligible patients, $241(85.2 \%)$ are created by the designated staff, and
$97(34.2 \%)$ are given to patients after definitive therapy (Table 1). The median age of the patient population was 64 years old, $25.2 \%$ lived in poverty, $13.4 \%$ lived in rural areas, and $36.7 \%$ identified as Hispanic. SCPs were given to patients by 17 different providers including gynecological oncologists, medical oncologists, surgical oncologists, and associated advanced practice providers. The average time from diagnosis to the patient completing definitive therapy, as measured by ordering of the SCP, was 248.3 days, and average time for patient to receive an SCP was 367.5 days.

Of the 97 SCPs eligible to be sent to PCPs, 75 (77.3\%) are mailed, faxed, or sent via EMR; $6(6.2 \%)$ had no associated PCP; and $8(8.2 \%)$ had PCPs in systems which do not accept unsolicited records (i.e., Veterans Affairs) (Fig. 2). Of the 34 (35\%) SCPs sent via mail, $6(6.2 \%)$ were received, and 3 (3.1\%) integrated. Of the 7 (13.9\%) SCPs sent via secure fax, $2(2.1 \%)$ were received, and both were integrated. Thus, only $8.3 \%$ were confirmed as received, and only $5.3 \%$ were integrated into the practice of those SCPs which were faxed or mailed. Qualitatively, multiple PCP offices reported that they lacked the technology to access the information on the $\mathrm{CD}$, could not locate the password, and/or were unaware of the secure fax process to receive patient medical records. The project was then put on hold due to the SARS-CoV-2 pandemic as many survivor visits were converted to telehealth visits, so patients could not receive their SCPs, and it was not practical to call PCP offices during the initial phase of the pandemic.

\section{Discussion}

The UNM CCC cares for patients from a broad catchment area who are of low socioeconomic status, ethnic/racial minority groups living in rural areas and was able to create and deliver SCPs to $34.2 \%$ of eligible patients after definitive treatment in the first year of the program. Considering national guidelines and various success rates of $11-86 \%$ in other non-randomized trials, these initial results for a new program are favorable. These SCPs were created for numerous cancer sites and given to patients by a broad range of providers approximately 1 year from diagnosis. Of the 97 SCPs sent to PCPs, $77.3 \%$ were sent by UNM CCC to a provider's office. However, only $8.3 \%$ were confirmed as received, and only $5.3 \%$ were integrated into the practice of those SCPs which were faxed or mailed.

Of the SCPs sent via EMR routing, it is not known what percentage was viewed by PCPs as there was no alert of the SCP arrival and the SCPs did not go into the inbox of the provider. In addition, the SCP was linked to the date of diagnosis that was approximately 1 year prior to the SCP delivery date so the SCP would be behind numerous more recent documents in the EMR. PCPs are frustrated with and have difficulty locating documents within EMR systems [41, 42]. Using 
Table 1 Characteristics of patients referred for survivorship care plan

\begin{tabular}{|c|c|c|c|c|c|}
\hline & SCP ordered & SCP created & SCP delivered to Patient & SCP delivered to PCP & $\begin{array}{l}\text { PCP received and } \\
\text { integrated SCP }\end{array}$ \\
\hline $\mathrm{N}(\%)$ & 283 & $241(85.2 \%)$ & $97(40.2 \%)$ & $75(77.3 \%)^{*}$ & $5(12.8 \%) \dagger$ \\
\hline $\begin{array}{l}\text { Time from diagnosis to SCP ordered } \\
\text { (days)-surrogate for completion } \\
\text { of definitive therapy }\end{array}$ & 248.3 & & 270.1 & 269.5 & \\
\hline Median Age & 64 years old & & 62 years old & 60 years old & \\
\hline Female & $226(79.8 \%)$ & & $86(88.7 \%)$ & $53(86.9 \%)$ & \\
\hline Below federal poverty level & $71(25.2 \%)$ & & & & \\
\hline Indigent & $59(21.8 \%)$ & & $16(16.5 \%)$ & $10(16.4 \%)$ & \\
\hline Rural & $38(13.4 \%)$ & & $3(3.1 \%)$ & $0(0 \%)$ & \\
\hline \multicolumn{6}{|l|}{ Race } \\
\hline Caucasian & $222(78.4 \%)$ & & $74(76.3 \%)$ & $47(77 \%)$ & \\
\hline Native American & $11(3.9 \%)$ & & $5(5.2 \%)$ & $1(1.6 \%)$ & \\
\hline Asian & $8(2.8 \%)$ & & $3(3.1 \%)$ & $2(3.2 \%)$ & \\
\hline African American & $6(2.1 \%)$ & & $1(1 \%)$ & $1(1.6 \%)$ & \\
\hline Declined to Answer/unavailable & $36(12.7 \%)$ & & $14(14.4 \%)$ & $5(8.2 \%)$ & \\
\hline \multicolumn{6}{|l|}{ Ethnicity } \\
\hline Hispanic & $103(36.7 \%)$ & & $40(41.2 \%)$ & $26(42.6 \%)$ & \\
\hline Not Hispanic & $166(58.7 \%)$ & & $43(44.3 \%)$ & $33(54.1 \%)$ & \\
\hline Declined to Answer/unavailable & $14(4.9 \%)$ & & $4(4.1 \%)$ & $1(1.6 \%)$ & \\
\hline \multicolumn{6}{|l|}{ Diagnosis } \\
\hline Breast cancer & $167(59.1 \%)$ & & $76(78.3 \%)$ & $45(73.8 \%)$ & \\
\hline Gynecological cancers ${ }^{*}$ & $32(10.8 \%)$ & & $9(9.3 \%)$ & $6(9.8 \%)$ & \\
\hline Prostate cancer & $21(7.4 \%)$ & & $6(6.2 \%)$ & $6(9.8 \%)$ & \\
\hline Colorectal cancer & $5(5.1 \%)$ & & $6(6.2 \%)$ & $4(6.6 \%)$ & \\
\hline Lymphoma $^{\S}$ & $4(4.8 \%)$ & & 0 & 0 & \\
\hline Other ${ }^{\text {II }}$ & $36(12.7 \%)$ & & 0 & 0 & \\
\hline
\end{tabular}

*Fourteen (18.7\%) of patient demographic data was missing from these seventy-five patients

$†$ These five SCP were assessed based on the thirty-nine SCP sent via fax or mail and not via EMR and thus the denominator is thirty-nine and not seventy-five

*Includes endometrial, cervical and ovarian cancer

$\S$ Includes Hodgkin lymphoma and non-Hodgkin lymphoma

${ }^{\text {II }}$ Includes all other cancer diagnosis not listed above

the EMR to care for survivors in the primary care setting has been difficult for PCPs as it is difficult to find these relevant documents and EMRs are not designed for survivorship care [43]. Of 88 PCPs surveyed who had received SCPs on their patients, most were unaware of the SCP in general (73\%) and had difficulty locating it (30\%) [44]. The same meta-analysis showed that most PCPs wanted to receive SCPs and used these in conversation with their patient, but the few studies which tracked PCP receipt and integration of SCP showed only $13 \%$ consistently received SCPs. Considering the above, it is very likely that most PCPs were not aware or could not find the SCP via the EMR and thus did not gain from the education and communication provided in the SCP. This study adds to the literature highlighting the difficulty of providing SCPs to PCPs and having PCPs integrate these documents in a real-world setting.

Most SCP implementation studies do not include delivery of the SCPs to PCPs [15], but those that do include this information describe intensive efforts to ensure that PCPs respond to the SCP and integrate it into their practice [22]. The majority of published programs that do deliver SCPs to PCPs does not routinely ensure PCP receipt and integration [33, 34, 45-49]. This is a significant flaw in the current model of survivorship care which current trials could further evaluate [50]. A future research hypothesis could focus on that part of the lack of proven benefit from SCPs to date is due to ineffective delivery and integration of SCPs to and by PCPs.

Several limitations in this study potentially hindered delivery of SCPs to PCPs and represent areas of future 
Fig. 2 SCP delivery to primary care providers

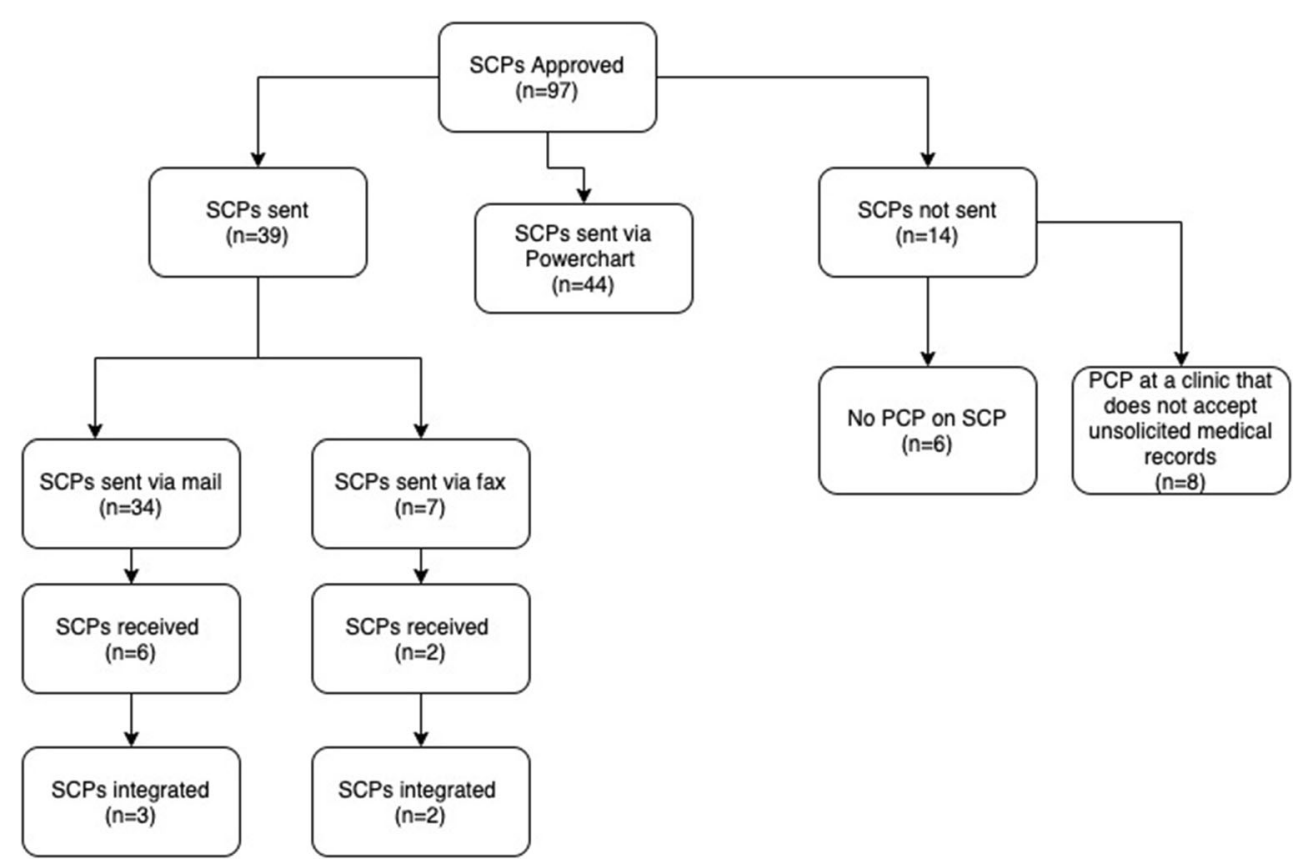

improvement and research. This program's results were compared against national standards and historical controls only. This system depends on providers identifying curative intent patients after definitive therapy who are appropriate for an SCP. This patient selection process is nuanced, so automation was not considered possible at this time but may be possible in the future. Maintaining privacy and security of patient information is critical, but the current system is cumbersome, and many PCP offices feel overwhelmed by the steps required to receive the SCPs. The UNM CCC either requires a secure fax number or sends a CD with a separately mailed password. Multiple PCP offices reported that they lacked the technology to access the information on the $\mathrm{CD}$, could not locate the password, and/or were unaware of the secure fax system for patient medical records likely rendering this approach ineffective. These limitations are expected to apply to other oncology practices. While the UNM CCC treats many cancers, several cancer types are treated by other UNM clinics, including thyroid cancer, pediatric cancers, and skin cancers. Recently, both dermatology and endocrinology clinics have been established within the UNM CCC to allow for better integration of services and consequently SCP delivery. Pediatric cancers are treated at the children's hospital with a separate procedure for SCP delivery, thereby creating redundant nonstandard processes. Additional limitations include the single institutional nature of this project, limited data of one year, and suspension of this project due to the SARS-CoV-2 pandemic. While data about SCP receipt and integration were gathered, data about the education PCPs received from the SCP was not.

This study shows that SCPs can be delivered to patients in a poor, rural, and minority patient population but that PCP receipt and integration of SCPs are poor. Future steps will involve EMR modifications to alert PCPs of SCP delivery, re-evaluation of the medical records distribution process, and assessing both patient and PCP perceptions of the SCP to ensure that SCPs are patient-centered, educational, and functional for PCP follow-up care with process monitoring quarterly. We continue to distribute SCPs and recommend their use despite the weakness demonstrated in our data. Further research is needed to ensure PCPs are receiving, learning from and integrating SCPs so that oncologists and primary care providers can coordinate survivorship care for cancer patients, thereby enhancing patient care and improving patient outcomes.

Availability of data and material NA Code availability NA

Authors' contributions All authors contributed to the study conception and design. Bernard Tawfik, Shoshana Adler Jaffe, Lisa Mohler, Jamina Oomen-Hajagos, and Zoneddy Dayao performed material preparation, data collection, and analysis. Bernard Tawfik wrote the first draft of the manuscript and all authors commented on previous versions of the manuscript. All authors read and approved the final manuscript.

Funding This research was partially supported by UNM Comprehensive Cancer Center Support Grant NCI P30CA118100 and the Behavioral Measurement and Population Sciences shared resource. Additional support came from the New Mexico Department of Health, with funding from the Centers for Disease Control and Prevention, Division of Cancer Prevention and Control, Cooperative Agreement Number NU58DP006280.

\section{Declarations}

Ethics approval This research was approved by the IRB. 
Consent to participate This research was deemed not human research so no consent was required.

Consent for publication All author consented to publication.

Conflict of interest The authors declare that they have no conflict of interest.

\section{References}

1. Miller KD, Siegel RL, Lin CC, Mariotto AB, Kramer JL, Rowland JH, Stein KD, Alteri R, Jemal A (2016) Cancer treatment and survivorship statistics, 2016. CA Cancer J Clin 66:271-289. https:// doi.org/10.3322/caac.21349

2. Yancik R (2005) population aging and cancer: a cross-national concern. Cancer J 11:437-441

3. Blanch-Hartigan D, Forsythe LP, Alfano CM, Smith T, Nekhlyudov L, Ganz PA, Rowland JH (2014) Provision and discussion of survivorship care plans among cancer survivors: results of a nationally representative survey of oncologists and primary care physicians. J Clin Oncol 32:1578-1585. https://doi.org/10. 1200/JCO.2013.51.7540

4. Kantsiper M, McDonald EL, Geller G, Shockney L, Snyder C, Wolff AC (2009) Transitioning to breast cancer survivorship: perspectives of patients, cancer specialists, and primary care providers. J Gen Intern Med 24:459-466. https://doi.org/10.1007/s11606009-1000-2

5. Nekhlyudov L, O'malley DM, Hudson SV (2017) Integrating primary care providers in the care of cancer survivors: gaps in evidence and future opportunities. Lancet Oncol 18:e30-e38. https:// doi.org/10.1016/S1470-2045(16)30570-8

6. Hewitt M, Greenfield S, Stovall E (n.d.) Chapter 4; Delivering Cancer Survivorship Care. In: From cancer patient to cancer survivor: lost in transition. The National Academies Press, Washington DC. https://doi.org/10.17226/11468

7. Baravelli C, Krishnasamy M, Pezaro C, Schofield P, Lotfi-Jam K, Rogers M, Milne D, Aranda S, King D, Shaw B, Grogan S, Jefford M (2009) The views of bowel cancer survivors and health care professionals regarding survivorship care plans and post treatment follow up. J Cancer Surviv 3:99-108. https://doi.org/10.1007/ s11764-009-0086-1

8. Mayer DK, Green M, Check DK, Gerstel A, Chen RC, Asher G, Wheeler SB, Hanson LC, Rosenstein DL (2015) Is there a role for survivorship care plans in advanced cancer? Support Care Cancer 23:2225-2230. https://doi.org/10.1007/s00520-014-2586-4

9. Oancea SC, Cheruvu VK (2016) Psychological distress among adult cancer survivors: importance of survivorship care plan. Support Care Cancer 24:4523-4531. https://doi.org/10.1007/ s00520-016-3291-2

10. Mayer DK, Nekhlyudov L, Snyder CF, Merrill JK, Wollins DS, Shulman LN (2014) American Society of Clinical Oncology clinical expert statement on cancer survivorship care planning. J Oncol Pract 10:345-351. https://doi.org/10.1200/JOP.2014.001321

11. CoC Standards and Resources (n.d.). American College of Surgeons https://www.facs.org/quality-programs/cancer/coc/ standards ().

12. ASCO (2011) Cancer Treatment and Survivorship Care Plans. CancerNet https://www.cancer.net/survivorship/follow-care-aftercancer-treatment/asco-cancer-treatment-and-survivorship-careplans (

13. Palmer SC, Stricker CT, Panzer SL, Arvey SA, Baker KS, Casillas J et al (2015) Outcomes and satisfaction after delivery of a breast cancer survivorship care plan: results of a multicenter trial. J
Oncol Pract 11:e222-e229. https://doi.org/10.1200/JOP.2014. 001404

14. McDonough AL, Rabin J, Horick N, Lei Y, Chinn G, Campbell EG et al (2019) Practice, preferences, and practical tips from primary care physicians to improve the care of cancer survivors. J Oncol Pract 15:e600-e606. https://doi.org/10.1200/JOP.18.00740

15. Jacobsen PB, DeRosa AP, Henderson TO, Mayer DK, Moskowitz CS, Paskett ED et al (2018) Systematic review of the impact of cancer survivorship care plans on health outcomes and health care delivery. J Clin Oncol 36:2088-2100. https://doi.org/10.1200/JCO. 2018.77.7482

16. van de Poll-Franse LV, Nicolaije KAH, Ezendam NPM (2017) The impact of cancer survivorship care plans on patient and health care provider outcomes: a current perspective. Acta Oncol 56:134-138. https://doi.org/10.1080/0284186X.2016.1266080

17. Forsythe LP, Parry C, Alfano CM, Kent EE, Leach CR, Haggstrom DA, Ganz PA, Aziz N, Rowland JH (2013) Use of survivorship care plans in the united states: associations with survivorship care. J Nat Cancer Inst 105:1579-1587. https://doi.org/10.1093/jnci/ $\operatorname{djt} 258$

18. Salz T, Oeffinger KC, McCabe MS, Layne TM, Bach PB (2012) Survivorship care plans in research and practice. CA Cancer J Clin 62:101-117. https://doi.org/10.3322/caac.20142

19. Merport A, Lemon SC, Nyambose J, Prout MN (2012) The use of cancer treatment summaries and care plans among Massachusetts physicians. Support Care Cancer 20:1579-1583. https://doi.org/10. 1007/s00520-012-1458-Z

20. Birken SA, Mayer DK (2017) Survivorship care planning: why is it taking so long? J Natl Compr Cancer Netw 15:1165-1169. https:// doi.org/10.6004/jncen.2017.0148

21. Birken SA, Mayer DK, Weiner BJ (2013) Survivorship care plans: prevalence and barriers to use. J Cancer Educ 28:290-296. https:// doi.org/10.1007/s13187-013-0469-x

22. Blaauwbroek R, Barf HA, Groenier KH, Kremer LC, van der Meer K, Tissing WJE, Postma A (2012) Family doctor-driven follow-up for adult childhood cancer survivors supported by a web-based survivor care plan. J Cancer Surviv 6:163-171. https://doi.org/10. 1007/s11764-011-0207-5

23. Dittus KL, Sprague BL, Pace CM, Dulko DA, Pollack LA, Hawkins NA, Geller BM (2014) Primary care provider evaluation of cancer survivorship care plans developed for patients in their practice. J Gen Pract 02. https://doi.org/10.4172/2329-9126. 1000163

24. Oeffinger KC, Hudson MM, Mertens AC, Smith SM, Mitby PA, Eshelman-Kent DA, Ford JS, Jones JK, Kamani S, Robison LL (2011) Increasing rates of breast cancer and cardiac surveillance among high risk survivors of childhood Hodgkin lymphoma following a mailed, one-page survivorship care plan. Pediatr Blood Cancer 56:818-824. https://doi.org/10.1002/pbc.22696

25. Hudson MM, Leisenring W, Stratton KK, Tinner N, Steen BD, Ogg S, Barnes L, Oeffinger KC, Robison LL, Cox CL (2014) Increasing cardiomyopathy screening in at-risk adult survivors of pediatric malignancies: a randomized controlled trial. J Clin Oncol 32: 3974-3981. https://doi.org/10.1200/JCO.2014.57.3493

26. Maly RC, Liang L-J, Liu Y, Griggs JJ, Ganz PA (2017) Randomized controlled trial of survivorship care plans among low-income, predominantly Latina breast cancer survivors. J Clin Oncol 35:1814-1821. https://doi.org/10.1200/JCO.2016.68.9497

27. Berman AT, DeCesaris CM, Simone CB, Vachani C, DiLullo G, Hampshire MK et al (2016) Use of survivorship care plans and analysis of patient-reported outcomes in multinational patients with lung cancer. J Oncol Pract 12:e527-e535. https://doi.org/10.1200/ JOP.2015.008904

28. Hill-Kayser CE, Vachani C, Hampshire MK, Jacobs LA, Metz JM (2009) An internet tool for creation of cancer survivorship care plans for survivors and health care providers: design, 
implementation, use and user satisfaction. J Med Internet Res 11: e39. https://doi.org/10.2196/jmir.1223

29. Hill-Kayser CE, Vachani C, Hampshire MK, Metz JM (2012) High level use and satisfaction with internet-based breast cancer survivorship care plans. Breast J 18:97-99. https://doi.org/10.1111/j. 1524-4741.2011.01195.x

30. Hill-Kayser CE, Vachani C, Hampshire MK, Jacobs LA, Metz JM (2009) Utilization of internet-based survivorship care plans by lung cancer survivors. Clin Lung Cancer 10:347-352. https://doi.org/10. 3816/CLC.2009.n.047

31. Szalda D, Schwartz L, Schapira MM, Jacobs L, Kim E, Vachani C, Metz J, Hill-Kayser C (2016) Internet-based survivorship care plans for adult survivors of childhood cancer: a pilot study. J Adolesc Young Adult Oncol 5:351-354. https://doi.org/10.1089/jayao. 2016.0026

32. Blinder VS, Norris VW, Peacock NW, Griggs JJ, Harrington DP, Moore A, Theriault RL, Partridge AH, on behalf of the American Society of Clinical Oncology Breast Cancer Registry Pilot Steering Group (2013) Patient perspectives on breast cancer treatment plan and summary documents in community oncology care. Cancer 119: 164-172. https://doi.org/10.1002/cncr.27856

33. Jefford M, Lotfi-Jam K, Baravelli C, Grogan S, Rogers M, Krishnasamy M, Pezaro C, Milne D, Aranda S, King D, Shaw B, Schofield P (2011) Development and pilot testing of a nurse-led posttreatment support package for bowel cancer survivors. Cancer Nurs 34:E1-E10. https://doi.org/10.1097/NCC.0b013e3181f22f02

34. Rushton M, Morash R, Larocque G, Liska C, Stoica L, DeGrasse C et al (2015) Wellness beyond cancer program: building an effective survivorship program. Curr Oncol 22:e419-e434. https://doi.org/ 10.3747/co.22.2786

35. Spain PD, Oeffinger KC, Candela J, McCabe M, Ma X, Tonorezos ES (2012) Response to a treatment summary and care plan among adult survivors of pediatric and young adult cancer. J Oncol Pract 8: 196-202. https://doi.org/10.1200/JOP.2011.000345

36. Survivorship Toolkit. Society of Gynecologic Oncology n.d. https://omssgo.wpengine.com/resources/survivorship-toolkit/ ().

37. Berg JW, Ross R, Latourette HB (1977) Economic status and survival of cancer patients. Cancer 39:467-477. https://doi.org/10. 1002/1097-0142(197702)39:2<467::AID-CNCR2820390215>3.0. $\mathrm{CO} ; 2-\mathrm{B}$

38. Bureau UC. Urban and Rural. The United States Census Bureau n.d. https://www.census.gov/programs-surveys/geography/ guidance/geo-areas/urban-rural.html ().

39. What is Rural? Introduction - Rural Health Information Hub n.d. https://www.ruralhealthinfo.org/topics/what-is-rural\#majordefinitions ().

40. Am I Rural? Tool - Rural Health Information Hub n.d. https://www. ruralhealthinfo.org/am-i-rural ().

41. Babbott S, Manwell LB, Brown R, Montague E, Williams E, Schwartz M, Hess E, Linzer M (2014) Electronic medical records and physician stress in primary care: results from the MEMO Study. J Am Med Inform Assoc 21:e100-e106. https://doi.org/10. 1136/amiajnl-2013-001875

42. Wilson CJ, Newman J, Tapper S, Lai S, Cheng PH, Wu FM, TaiSeale M (2013) Multiple locations of advance care planning documentation in an electronic health record: are they easy to find? J Palliat Med 16:1089-1094. https://doi.org/10.1089/jpm.2012.0472

43. Rubinstein EB, Miller WL, Hudson SV, Howard J, O’Malley D, Tsui J, Lee HS, Bator A, Crabtree BF (2017) Cancer survivorship care in advanced primary care practices. JAMA Intern Med 177: 1726-1732. https://doi.org/10.1001/jamainternmed.2017.4747

44. Donohue S, Haine JE, Li Z, Feldstein DA, Micek M, Trowbridge ER, Kamnetz SA, Sosman JM, Wilke LG, Sesto ME, Tevaarwerk AJ (2019) Cancer survivorship care plan utilization and impact on clinical decision-making at point-of-care visits with primary care: results from an engineering, primary care, and oncology collaborative for survivorship health. J Cancer Educ 34:252-258. https://doi. org/10.1007/s13187-017-1295-3

45. Boekhout AH, Maunsell E, Pond GR, Julian JA, Coyle D, Levine MN et al (2015) A survivorship care plan for breast cancer survivors: extended results of a randomized clinical trial. J Cancer Surviv 9:683-691. https://doi.org/10.1007/s11764-015-0443-1

46. Grunfeld E, Julian JA, Pond G, Maunsell E, Coyle D, Folkes A et al (2011) Evaluating survivorship care plans: results of a randomized, clinical trial of patients with breast cancer. J Clin Oncol 29:47554762. https://doi.org/10.1200/JCO.2011.36.8373

47. Grunfeld E, Mant D, Yudkin P, Adewuyi-Dalton R, Cole D, Stewart J, Fitzpatrick R, Vessey M (1996) Routine follow up of breast cancer in primary care: randomised trial. BMJ 313:665-669. https://doi.org/10.1136/bmj.313.7058.665

48. Nicolaije KAH, Ezendam NPM, Vos MC, Pijnenborg JMA, Boll D, Boss EA et al (2015) Impact of an automatically generated cancer survivorship care plan on patient-reported outcomes in routine clinical practice: longitudinal outcomes of a pragmatic, cluster randomized trial. J Clin Oncol 33:3550-3559. https://doi.org/10. 1200/JCO.2014.60.3399

49. Grunfeld E, Levine MN, Julian JA, Coyle D, Szechtman B, Mirsky $\mathrm{D}$ et al (2006) Randomized trial of long-term follow-up for earlystage breast cancer: a comparison of family physician versus specialist care. J Clin Oncol 24:848-855. https://doi.org/10.1200/JCO. 2005.03.2235

50. Comparing Three Cancer Survivorship Care Plan Delivery Models 2015. https://www.pcori.org/research-results/2015/comparingthree-cancer-survivorship-care-plan-delivery-models ().

Publisher's note Springer Nature remains neutral with regard to jurisdictional claims in published maps and institutional affiliations. 